\title{
Bile Salt Transport after Selective Damage to Acinar Zone 3 Hepatocytes by Bromobenzene in the Rat
}

\author{
Jorge J. Gumucio, Michael E. Katz, Deborah L. Miller, Charles P. Balabaud, \\ Jeremy M. Greenfield, AND Renate M. Wagner \\ Department of Internal Medicine, Section of Gastroenterology, The University of Michigan \\ Medical School, Ann Arbor, Michigan 48109
}

Received December 12, 1978; accepted March 24, 1979

\begin{abstract}
Bile Salt Transport after Selective Damage to Acinar Zone 3 Hepatocytes by Bromobenzene in the Rat, Gumucio, J. J., Katz, M. E., Miller, D. L., Balabaud, C. P., GreenField, J. M., And WaGner, R. M. (1979). Toxicol. Appl. Pharmacol. 50, 77-85. To quantitate the contribution of acinar zone 3 hepatocytes (centrilobular cells) to the transport of physiological concentrations of taurocholate, selective acinar zone 3 cell damage was induced in female rats by the administration of bromobenzene. Forty-eight hours later, livers were perfused in situ. Oxygen consumption, gluconeogenesis, transport of $\left[{ }^{14} \mathrm{C}\right]$ taurocholate into bile, bile flow and capacity for removal of indocyanine green were assessed. The removal of single doses of $\left[{ }^{14} \mathrm{C}\right]$ taurocholate injected into the portal vein at loads of 0.025 and $0.11 \mu \mathrm{mol} / \mathrm{kg}$ was then measured. Bromobenzene-treated livers removed $80-85 \%$ of the injected dose while control livers removed about $98 \%$. The percentage of the injected dose removed by each group at each load of taurocholate remained fairly constant. In separate experiments, $\left[{ }^{14} \mathrm{C}\right]$ taurocholate was administered in successive single injections at loads between 0.20 and $75 \mu \mathrm{mol} / \mathrm{kg}$. The percentage of the injected dose removed remained constant and was similar to that observed at lower loads of taurocholate until a dose of $1.0 \mu \mathrm{mol} / \mathrm{kg}$ was used. At higher loads, the percentage of the injected dose removed decreased progressively, suggesting that the uptake process was reaching saturation. These results showed that acinar zone 3 hepatocytes contributed to the removal of $13-18 \%$ of a physiological load of taurocholate. Furthermore, a $50 \%$ decrease in bile flow was observed after bromobenzene administration. This suggested that damage to the centrilobular area is followed by alterations in bile flow and by the passage of at least $13-18 \%$ of the bile salts reaching the acinus into the general circulation. In addition, taurocholate removal after carbon tetrachloride-induced damage to the centrilobular area was studied. Twelve to eighteen percent of the injected dose of $\left[{ }^{14} \mathrm{C}\right]$ taurocholate was found in the hepatic vein effluent, values similar to the results obtained after bromobenzeneinduced damage.
\end{abstract}

The hepatic acinus, the microcirculatory unit of the liver, is composed of hepatocytes receiving blood from a single portal venule and hepatic arteriole (Rappaport, 1975). Portal blood, after traversing the acinar sinusoids, is drained by two or more terminal hepatic venules. The concentration of the incoming metabolites in sinusoidal blood is therefore highest at the acinar inlet or zone 1 (periportal hepatocytes), while their concentration at the outlet or zone 3 (the centrilobular area) depends on the amount removed by periportal and midzonal hepatocytes (acinar zone 2). On this basis, Goresky et al. (1973) postulated that concentration gradients of bile salts in sinusoidal blood should occur between periportal (acinar zone 1) and centrilobular areas (acinar zone 3). However, 
this hypothesis has not yet been verified, as the transport of bile salts by either acinar zone 1 or acinar zone 3 hepatocytes has not been quantified.

Bromobenzene, a compound known to induce selective acinar zone 3 necrosis (Reid and Krishna, 1973), has been previously used to study the contribution of acinar zones 1 and 3 to bile secretion (Gumucio et al., 1978a). Those studies showed that the capacity for bile salt transport was distributed among hepatocytes of all acinar zones. However, the contribution of each zone to bile salt transport was not quantified.

The objective of the present study is to assess the contribution of acinar zone 3 hepatocytes to the transport of physiological concentrations of taurocholate by the intact liver. The experimental design used was to determine the transport of taurocholate by the perfused rat liver after selective damage by either bromobenzene or carbon tetrachloride.

\section{METHODS}

\section{Experimental design}

Female Charles Rivers rats weighing between 180 and $220 \mathrm{~g}$ werc injected ip with bromobenzene dissolved in corn oil $(3.8 \mathrm{mmol} / \mathrm{kg})$ between 9 and $11 \mathrm{AM}$. Control rats received an equal volume of corn oil $(1.0 \mathrm{ml} / \mathrm{kg})$. Forty-eight hours later, at the time of maximal morphological damage to acinar zone 3 (Rcid and Krishna, 1973; Gumucio et al., 1978a), nonfasted rats were anesthetized with sodium pentobarbital ( $40 \mathrm{mg} / \mathrm{kg}$, ip). The abdomen was opened and a loose ligature placed around the inferior vena cava (IVC) above the right renal vein; 100 units of heparin (sodium salt) was then injected into the IVC. After $3 \mathrm{~min}$, two loose ligatures were placed around the portal vein, one above the entrance of the superior mesenteric vein and another above the entrance of the splenic vein. The portal vein was opened and rapidly cannulated with PE 205, and the ligature was tied. The ligature around the IVC was then tied and severed below the right kidney. Perfusion was started at a rate of $20 \mathrm{ml} / \mathrm{min}$. The thorax was rapidly opened, an incision made in the right atrium and the rate of perfusion increased to maintain a perfusion pressure of $10-15 \mathrm{~cm}$ of water (Tavoloni et al., 1978) (usually about $25-30 \mathrm{ml} / \mathrm{min}$ in both groups). This was followed by cannulation of the thoracic segment of the IVC. The tip of this cannula (PE 205, $15 \mathrm{~cm}$ long) was maintained below the level of the liver to assure fast drainage of this open system of perfusion (single passage system). The perfusate consisted of Hanks buffer (Hanks and Wallace, 1949). This buffer was equilibrated constantly with $95 \% \mathrm{O}_{2}$ and $5 \% \mathrm{CO}_{2}$ and the temperature maintained at $37^{\circ} \mathrm{C}$. The $\mathrm{pH}$ was adjusted to 7.42 by the addition of $\mathrm{NaHCO}_{3}$. The osmolality was $315 \mathrm{mOsm} /$ liter. The perfusion apparatus was a modification of the system described by Scholz (1968). The perfusate was moved via a pump from a double walled cylinder, through double-walled coiled tubing to the portal vein cannula. Water at $37^{\circ} \mathrm{C}$ was constantly circulated through the outer walls of the system, assuring a temperature of $37^{\circ} \mathrm{C}$ at the tip of the portal vein cannula.

During the initial experiments, it was noted that the small intraabdominal segment of the IVC which runs from the ligature above the renal vein across the posterior surface of the liver became engorged during perfusion. To prevent the development of a stagnant loop, a cannula (PE 205) was introduced into this segment of the IVC and tied immediately above the previous ligature. Using a Buchler peristaltic pump, this segment was emptied into the IVC cannula by infusion with Hanks buffer at a rate of $2.5 \mathrm{ml} / \mathrm{min}$.

To determine that these livers were functionally active, the following four measurements were performed.

Oxygen consumption. $\mathrm{pO}_{2}$ was determined by means of an oxygen electrode (I.L. 813, Lexington, Mass.) in samples taken from the portal vein and IVC cannulas 15 min after initiation of the perfusion with Hanks buffer. The oxygen consumption was calculated from these values as described by Tavoloni et al. (1978).

Changes in bile flaw after sodium taurocholate infusion. In separate experiments, the proximal common bile duct (above the pancreas) was cannulated using a polyethylene cannula (PE 10) immediately after initiation of the perfusion. Five minutes later, bile was collected in preweighed microtubes (Bio-Rad 1.5-ml tubes) for $10 \mathrm{~min}$. An infusion of sodium taurocholate (added to the Hanks buffer) was then initiated at a rate of $4.0 \mu \mathrm{mol} / \mathrm{kg} / \mathrm{min}$ for 30 min. Bile was collected throughout this period.

The capacity for removal of indocyanine green (ICG). To assess the functional mass available after bromobenzene administration, ICG was administered in successive injections $5 \mathrm{~min}$ after the perfusion with Hanks buffer was initiated. Each liver received four injections into the portal vein cannula at dosages of $3.0,4.0,6.0$, and $10.0 \mathrm{mg} / \mathrm{kg}$. Each dose was administered as a single injection of $1 \mathrm{sec}$ or less duration. The order of injection $(3.0$ to $10 \mathrm{mg} / \mathrm{kg}$ ) was constant in all experiments. The appearance of ICG in the outflow was followed continuously at 15-sec intervals for $3 \mathrm{~min}$. Five additional minutes elapsed between the time ICG disappeared from the outflow 
and the next injection. ICG was measured in the outflow at $800 \mathrm{~nm}$ in a Gilford spectrophotometer (model 250) after appropriate dilutions were made in saline containing bovine albumin for stabilization (Paumgartner et al., 1970). As more than 95\% of the recovered ICG appeared in the outflow during the initial $75 \mathrm{sec}$, the amount measured during this time was used to calculate the removal of ICG by the liver.

Rate of gluconeogenesis in isolated liver cells. The rate of gluconeogenesis of hepatocytes showing no morphological damage was determined to verify the functional integrity of periportal and midzonal hepatocyles. Either bromobenzene or corn oil was administered to female rats, as described above, and liver cell subpopulations probably corresponding to acinar zone 1 or acinar zone 3 hepatocytes were isolated $48 \mathrm{hr}$ later (Gumucio et al, 1978b). Isolated liver cells equilibrating at densities of 1.17 , representing damaged hepatocytes (Gumucio et all, 1978b), were studied separately. Cells were examined prior to the incubation by light microscopy with and without the addition of trypan blue, as described previously (Gumucio et al., 1978b). Gluconeogenesis was assayed according to Cornell and Filkins (1974), using $10 \mathrm{~mm}$ lactate as substrate. Glucose produced during the $2 \mathrm{hr}$ of incubation was measured by the glucose oxydase method (Statzyme glucose, Worthington Biochemical). Cell protein was determined according to Lowry et al. (1951).

$\left[{ }^{14} \mathrm{C}\right]$ Taurocholate removal at physiological concentrations. In these initial experiments, $\left[{ }^{14} \mathrm{C}\right]$ taurocholate was administered into the portal vein cannula as a single injection, within a time lapse of $1 \mathrm{sec}$ or less, $5 \mathrm{~min}$ after initiation of perfusion. The volume of the injection was constant $(0.25 \mathrm{ml})$, while the dosage varied between $0.025,0.04,0.06$, and $0.11 \mu \mathrm{mol} / \mathrm{kg}$. Each liver received only one dose. The exact amount of $\left[{ }^{14} \mathrm{C}\right]$ taurocholate injected was determined by the difference in weight of the 1-ml syringe before and after the injection. The appearance of $\left[{ }^{14} \mathrm{C}\right]$ taurocholate in the outflow was determined continuously at 15 -sec intervals for $3 \mathrm{~min}$.

To test whether $\left[{ }^{14} \mathrm{C}\right]$ taurocholate not appearing in the outflow had actually been removed by a liver capable of transporting bile salts into bile, the recovery of ${ }^{14} \mathrm{C}$ radioactivity in liver homogenates and in bile was studied. For this purpose, a bile fistula was prepared as described above, the liver perfused for 4 min and $\left[{ }^{14} \mathrm{C}\right]$ taurocholate injected as a single dose of $0.04 \mu \mathrm{mol} / \mathrm{kg}(2.3 \mu \mathrm{Ci} / \mathrm{kg}) .{ }^{14} \mathrm{C}$ radioactivity appearing in the outflow was determined as described. In addition, to stimulate bile flow (which was very low in the absence of bile salts) a 30-min infusion of unlabeled sodium taurocholate $(4.0 \mu \mathrm{mol} / \mathrm{kg} / \mathrm{min})$ was initiated $3 \mathrm{~min}$ after the injection of the isotope. Bile was collected from the moment $\left[{ }^{14} \mathrm{C}\right]$ taurocholate was injected. At the end of the sodium taurocholate infusion the liver was removed, weighed, and homogenized in distilled water. Radioactivity in liver homogenates was counted after digestion with hyamine hydroxide for $48 \mathrm{hr}$ at $30^{\circ} \mathrm{C}$. Radioactivity in the outflow, in liver homogenates, and in bile was counted in $10 \mathrm{ml}$ of Bray's scintillation mixture in a liquid scintillation spectrometer (Packard, Tri-Carb). Efficiency for ${ }^{14} \mathrm{C}$ in Bray's solution was $67.5 \%$. Quenching was determined by internal standardization using $\left[{ }^{14} \mathrm{C}\right]$ toluene as standard (New England Nuclear).

$\left[{ }^{14} \mathrm{C}\right]$ Taurocholate removal at high concentrations. In these experiments, each liver received five consecutive injections of $\left[{ }^{14} \mathrm{C}\right]$ taurocholate in progressive doses between 0.2 and $75 \mu \mathrm{mol} / \mathrm{kg}$ into the portal vein cannula. After each injection (of $1 \mathrm{sec}$ or less in duration), the radioactivity was measured continuously in the outflow at 15-sec intervals for $2 \mathrm{~min}$. Five minutes after the radioactivity had disappeared from the outflow, the next dose of $\left[{ }^{14} \mathrm{C}\right]$ taurocholate was injected. Solutions of $\left[{ }^{14} \mathrm{C}\right]$ taurocholate with known amounts of sodium taurocholate were prepared in saline containing $2 \%$ albumin. The volume of injection was $1.0 \mathrm{ml} / \mathrm{kg}$. Again, the radioactivity appearing in the outflow during the initial $75 \mathrm{sec}$ was used to calculate the amount removed by the liver, as it represented more than $88 \%$ of the radioactivity at any load.

Assessment of damage induced by bromobenzene. The extent of tissue damage was quantified by measuring the volume fraction of necrosis according to Chalkley (1944), as previously described (Gumucio et al., 1978a).

Experiments with carbon tetrachloride. To test whether results obtained after bromobenzene might be found with other centrilobular toxins, additional experiments were performed using carbon tetrachloride (Oberling and Rouiller, 1967).

Female rats weighing $180-210 \mathrm{~g}$ received $3.9 \mathrm{mmol} /$ $\mathrm{kg}$ carbon tetrachloride dissolved in corn oil, ip. Control rats were injected with the same volume $(1.5 \mathrm{ml} / \mathrm{kg}$, ip) of corn oil. All experiments were performed between 25 and $28 \mathrm{hr}$ after the administration of carbon tetrachloride. Livers were perfused in situ with Hanks buffer and, 5 min after initiation of the perfusion, $\left[{ }^{14} \mathrm{C}\right]$ taurocholate was injected as a single bolus ( $1 \mathrm{sec}$ or less in duration) into the portal vein cannula. Each liver received five consecutive $\left[{ }^{14} \mathrm{C}\right]-$ taurocholate injections at doses of $0.11,0.2,0.3,1,0$, 12.5 , and $75 \mu \mathrm{mol} / \mathrm{kg}$. The system of perfusion, the determination of radioactivity in the outflow, timing of collections, and time between doses were the same as those described for high concentrations of taurocholate after bromobenzene administration. The volume fraction of necrosis after carbon tetrachloride was determined in rats injected in parallel with the ones perfused, as described earlier. In separate 
experiments, a bile fistula was prepared before initiation of the perfusion with Hanks buffer and bile flow determined during the initial $15 \mathrm{~min}$ of perfusion of these carbon tetrachloride-treated livers.

\section{Chemicals and Isotopes}

Bromobenzene (gold label) was obtained from Aldrich Chemicals. [Carbonyl $-{ }^{14} \mathrm{C}$ ]taurocholic acid, sodium salt, was purchased from Amersham/Searle Corporation. Its radiochemical purity $(99 \%)$ was assessed by thin-layer chromatography on silica gel using chloroform : methanol : ammonia : water $(20$ : $15: 1: 2)$ and $n$-butanol : water : acetic acid (12:5: 3). Its specific gravity was $59 \mathrm{mCi} / \mathrm{mmol}$. Polyethylene cannulas (PE) were obtained from Clay Adams. Taurocholic acid, sodium salt, was obtained from Calbiochem (grade A). It was purified prior to its infusion by thin-layer chromatography (Heaton, 1972). ICG was purchased from ICN Pharmaceuticals, Plainview, New York. Carbon tetrachloride (spectranalyzed) was obtained from Fischer Scientific Company.

\section{Statistics}

An analysis of variance was used to determine the statistical significance of the data presented in Figs. 1, 2, 4, 6, and 7. Means were compared using Scheff's confidence intervals (MIDAS program, Statistical Rescarch Laboratory, The University of Michigan). Student's $t$ test was used to assess differences between means in the remainder of the data. $p$ values higher than 0.05 were considered not significant (NS).

\section{RESULTS}

\section{Volume Fraction of Necrosis}

The volume fraction of necrosis measured $48 \mathrm{hr}$ after the administration of bromobenzene was $35 \pm 3.7 \%$ (SE, $n=8$ ). Twentyfour hours after carbon tetrachloride injection, the volume fraction of necrosis was $21.56 \pm 2.7 \%$ (SE, $n=6$ ), significantly lower than after bromobenzene $(p<0.05)$.

\section{Oxygen Consumption}

The oxygen consumption ( $\mu \mathrm{mol} / \mathrm{g}$ liver/ $\min$ ) was $2.34 \pm 0.3(\mathrm{SE})$ in controls and $2.18 \pm 0.27$ after bromobenzene administration $(p=\mathrm{NS})$.

\section{Bile Flow}

As shown in Fig. 1 and as previously found in experiments performed in vivo, bile flow measured during the basal period was

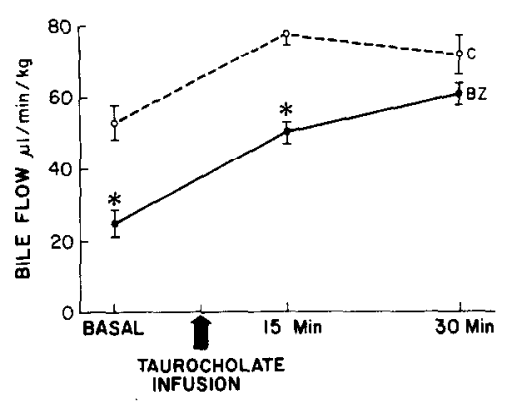

Fig. 1. Changes in bile flow after sodium taurocholate infusion. Taurocholate was infused continuously at a rate of $4.0 \mu \mathrm{mol} / \mathrm{kg} / \mathrm{min}$ for $20 \mathrm{~min}$. Values are means $\pm \mathrm{SE} ; n=6$. Basal $=$ bile collection prior to taurocholate infusion. An asterisk indicates $p<0.001$ compared to controls. $\mathrm{C}=$ Control; $\mathrm{BZ}=$ bromobenzene.

less after bromobenzene administration than in controls. Following the continuous infusion of unlabeled sodium taurocholate, bile flow increased significantly in both groups. The difference in bile flow noticed during the basal period was still present $5 \mathrm{~min}$ after taurocholate infusion. After $30 \mathrm{~min}$, however, differences in bile flow were not statistically significant.

\section{Rate of Gluconeogenesis}

The rate of gluconeogenesis from lactate $(\mu \mathrm{mol} / \mathrm{g}$ protein $/ \mathrm{min})$ determined in isolated hepatocytes equilibrated at a density of 1.12 was $1.35 \pm 0.21(\mathrm{SE}, n=8)$ in bromobenzene-treated animals and 1.28 \pm 0.17 ( $n=$ 12 ) in controls ( $p=N S$ ). Glucose production from lactate was not detectable in damaged cells equilibrating at a density of 1.17 in any of the groups.

\section{Assessment of the Functional Mass Available after Bromobenzene Administration}

As shown in Fig. 2, the highest measured capacity for ICG removal (attained with injection of $6 \mathrm{mg} / \mathrm{kg}$ in both groups) was $3.9 \pm 0.22(\mathrm{SE}) \mathrm{mg} / \mathrm{kg}$ in controls and $2.0 \pm$ $0.15 \mathrm{mg} / \mathrm{kg}$ after bromobenzene $(p<0.01$, $n=5$ ). As illustrated in Fig. 3, while the volume fraction of necrosis observed in acinar zone 3 after bromobenzene administra- 


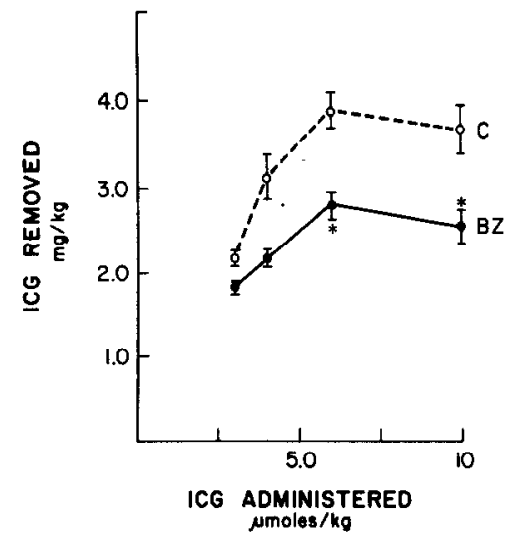

FIG. 2. Removal of indocyanine green (ICG). Values are means $\pm \mathrm{SE} ; n=5$. An asterisk indicates $p<0.01$ compared to control. $\mathrm{C}=$ Control; $\mathrm{BZ}=$ bromobenzene.

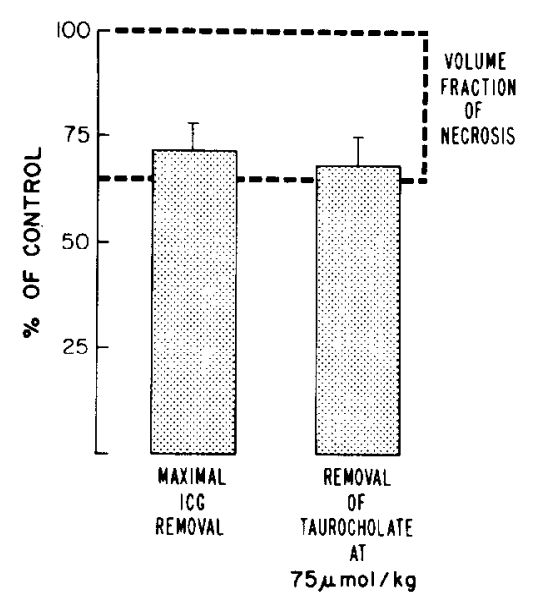

FIG. 3. Comparison between the volume fraction of necrosis and the reduction in the capacities for removal of ICG and taurocholate after bromobenzene administration. Values are means $\pm S E$; $n=6-8$. The rectangle at the top (dotted lines) represents the volume fraction of necrosis measured $48 \mathrm{hr}$ after bromobenzene administration $(35 \% \pm$ $3.7 \%$, SE, $n=8$ ).

tion was approximately $35 \%$, the reduction in the maximal capacity for ICG removal was about $28 \%$, indicating a good agreement between morphological and functional assessment of cell integrity.

$\left[{ }^{14} \mathrm{C}\right]$ Taurocholate Removal at Near Physiological Concentrations

The total radioactivity appearing in the

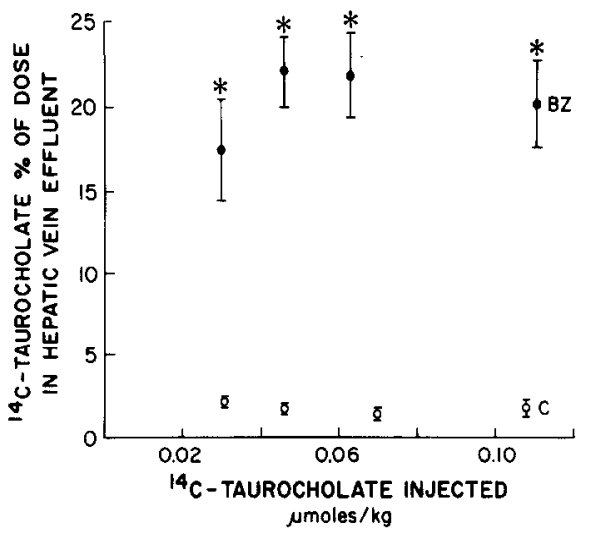

Fig. 4. Percentage of the injected dose of $\left[{ }^{14} \mathrm{C}\right]-$ taurocholate (physiological loads) appearing at the outlet. Values are means $\pm \mathrm{SE} ; n=6-8$. An asterisk indicates $p<0.0001$ compared to control. $\mathrm{C}=$ Control; $\mathbf{B Z}=$ bromobenzene.

outflow during the initial $75 \mathrm{sec}$ is presented in Fig. 4 as percentage of the injected dose of $\left[{ }^{14} \mathrm{C}\right]$ taurocholate. Of the injected dose, $15-20 \%$ was recovered in the effluent after bromobenzene administration, while about $2 \%$ appeared in the outflow in control livers. These percentages remained fairly constant between acinar loads of 0.025 and $0.11 \mu \mathrm{mol} /$ $\mathrm{kg}$.

To test the assumption that the radioactivity not appearing in the outflow had been removed by a liver capable of transporting bile salts, the secretion of $\left[{ }^{14} \mathrm{C}\right]-$ taurocholate into bile was studied. As shown in Fig. 5 , the ${ }^{14} \mathrm{C}$ radioactivity not accounted for in the outflow was almost completely recovered in bile with less than $2 \%$ remaining in liver homogenates. This indicated that these perfused livers were not passively trapping taurocholate but were capable of transporting bile salts from the sinusoidal compartment into bile.

\section{$\left[{ }^{14} \mathrm{C}\right]$ Taurocholate Removal at Higher Con- centrations}

Figure 6 shows the percentage of the injected dose removed after successive [ $\left[{ }^{14} \mathrm{C}\right]-$ taurocholate injections between 0.2 and $75 \mu \mathrm{mol} / \mathrm{kg}$. Values previously obtained at low concentrations of taurocholate have 


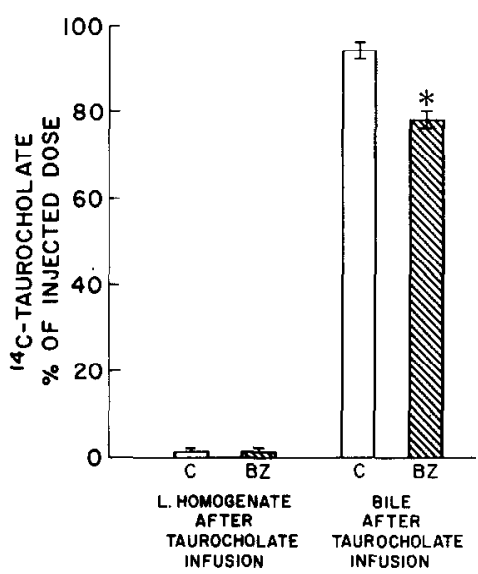

FIG. 5. Recovery of $\left[{ }^{14} \mathrm{C}\right]$ taurocholate in liver homogenates and in bile. Unlabeled sodium taurocholate $(4.0 \mu \mathrm{mol} / \mathrm{kg} / \mathrm{min})$ was infused $3 \mathrm{~min}$ after the administration of $\left[{ }^{14} \mathrm{C}\right]$ taurocholate. Values are means $\pm \mathrm{SE} ; n=6$. An asterisk indicates $p<0.01$ compared to control.

been added to the initial part of the graph, on the left, to illustrate that the percentage of the dose removed remained constant, even though two different experimental designs were used. This percentage remained at about $98 \%$ in controls and approximately $80 \%$ after bromobenzene until a dose of $0.1 \mu \mathrm{mol} / \mathrm{kg}$ was injected. Between this dose and $75 \mu \mathrm{mol} / \mathrm{kg}$, the percentage of the

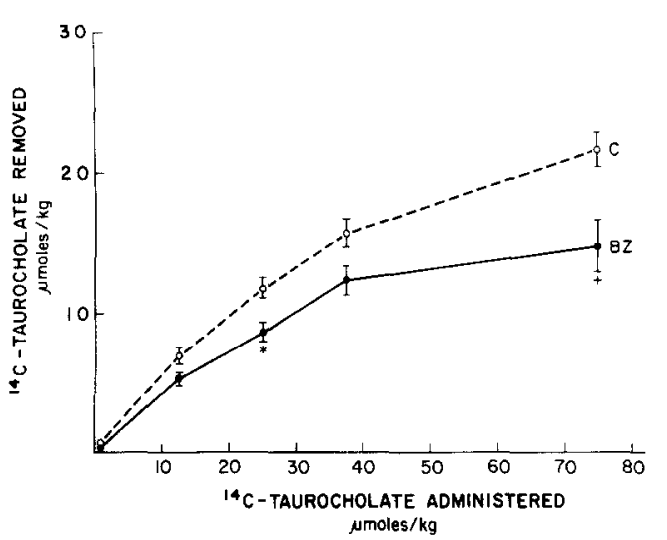

Fig. 7. Removal of $\left[{ }^{14} \mathrm{C}\right]$ taurocholate in absolute amounts. Values are means $\pm \mathrm{SE} ; n=6$. An asterisk indicates $p<0.01$ compared to controls. A cross indicates $p<0.0001$ compared to controls. $\mathrm{C}=$ Controls; $\mathrm{BZ}=$ bromobenzene.

dose removed became progressively lower, as expected from a system reaching saturation. That this was the case is illustrated in Fig. 7. A curvilinear relationship was obtained in both groups when the absolute amount of $\left[{ }^{14} \mathrm{C}\right]$ taurocholate removed by livers was calculated for each load of taurocholate. Livers of bromobenzene-treated rats seemed to have reached saturation of the uptake process, while control livers probably did not.

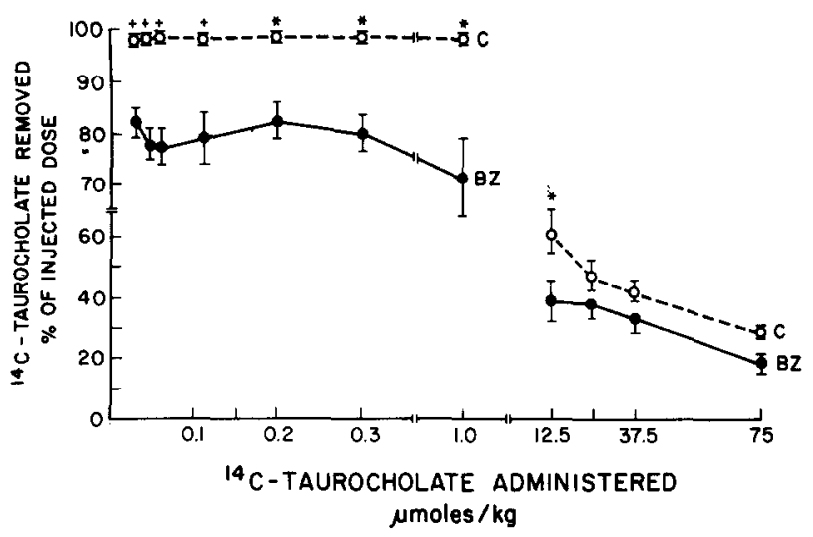

FIG. 6. Percentage of the injected dose of $\left[{ }^{14} \mathrm{C}\right]$ taurocholate removed. Results obtained at physiological loads $(0.025$ to $0.11 \mu \mathrm{mol} / \mathrm{kg})$ are also presented to illustrate that the amount of $\left[{ }^{14} \mathrm{C}\right]$ taurocholate removed was independent of the experiments design (either single or multiple injections). Values are means $\pm \mathrm{SE} ; n=6-8$. An asterisk indicates $p<0.005$ compared to controls. A cross indicates $p<0.0001$ compared to controls. $\mathrm{C}=$ Controls; $\mathrm{BZ}=$ bromobenzene. 
A $30 \%$ reduction in the removal of $\left[{ }^{14} \mathrm{C}\right]-$ taurocholate was noted at the highest load tested $(75 \mu \mathrm{mol} / \mathrm{kg})$. Figure 3 compares this reduction in taurocholate removal with the volume fraction of necrosis as well as with the decreased removal of ICG previously observed.

\section{$\left[{ }^{14} \mathrm{C}\right]$ Taurocholate Removal after Carbon Tetrachloride}

The percentage of the injected $\left[{ }^{14} \mathrm{C}\right]-$ taurocholate removed by carbon tetrachloride livers is shown in Table 1 . In agreement with the smaller volume fraction of necrosis observed with this toxicant, a higher percentage of the injected taurocholate was removed $(82-87 \%$ at low doses of taurocholate) than after bromobenzene treatment. At higher taurocholate loads, the percentage of the injected dose removed decreased progressively, as previously observed in both controls and bromobenzene-treated livers. Thus, the amount of taurocholate removed at a load of $75 \mu \mathrm{mol} / \mathrm{kg}$ was $16.4 \pm 2.1$ (SE) $\mu \mathrm{mol} / \mathrm{kg}(n=7)$, compared with $21.8 \pm$ $1.2 \mu \mathrm{mol} / \mathrm{kg}(n=7)$, removed in controls $(p<0.05)$.

TABLE 1

Removal of $\left[{ }^{14} \mathrm{C}\right]$ Taurocholate after Carbon TETRACHLORIDE ADMINISTRATION

\begin{tabular}{|c|c|c|}
\hline $\begin{array}{c}{\left[{ }^{14} \mathrm{C}\right] \text { Taurocholate }} \\
\text { administered }\end{array}$ & $\begin{array}{r}\text { Perce } \\
{\left[{ }^{14} \mathrm{C}\right] \mathrm{tal}} \\
\text { rem }\end{array}$ & $\begin{array}{l}\text { e of } \\
\text { holate } \\
\mathrm{d}^{a}\end{array}$ \\
\hline$(\mu \mathrm{mol} / \mathrm{kg})$ & By liver & $p$ value $^{b}$ \\
\hline 0.04 & $87.8 \pm 2.8$ & NS \\
\hline 0.11 & $88.4 \pm 1.1$ & NS \\
\hline 0.3 & $82.1 \pm 1.7$ & NS \\
\hline 1.0 & $77.1 \pm 2.6$ & $<0.001$ \\
\hline 12.5 & $\begin{array}{l}42.4 \pm 4.5 \\
26.2 \pm 5.3\end{array}$ & $<0.025$ \\
\hline
\end{tabular}

Means $\pm \mathrm{SE}, n=6$.

${ }^{b} p$ value indicates differences between successive taurocholate loads.
Bile flow determined during the initial 15 min of perfusion with Hanks buffer was $18.6 \pm 6.6 \quad$ (SE) $\mu \mathrm{l} / \mathrm{kg} / \mathrm{min} \quad(n=9)$, after carbon tetrachloride administration and $54.7 \pm 2.7$ (SE) $\mu \mathrm{l} / \mathrm{kg} / \mathrm{min}(n=9)$, in controls $(p<0.001)$.

\section{DISCUSSION}

The contribution of acinar zone 3 hepatocytes to the transport of physiological loads of taurocholate has been determined using the perfused rat liver after acinar zone 3 necrosis induced by bromobenzene. In this approach, it was assumed that livers perfused only with Hanks buffer were functionally active and remained so throughout the experiments. Oxygen consumption was similar in both groups and within values reported by others using perfusates containing red blood cells (Tavoloni et al., 1978). In addition, livers of both control and bromobenzenetreated rats responded to a continuous infusion of sodium taurocholate by increasing bile flow over a 30 -min period, indicating that the secretion of water in response to bile salt transport was preserved. Furthermore, livers from each group transported $\left[{ }^{14} \mathrm{C}\right]-$ taurocholate into bile in an amount equal to the difference between the amount injected into the portal vein and the radioactivity recovered in the outflow. Thus, these livers were functionally active and, specifically, were capable of transporting bile salts into bile.

It was also assumed that the damage induced by bromobenzene was restricted to the centrilobular cell area or acinar zone 3 of Rappaport (1975). While it has been shown by both light (Reid and Krishna, 1973) and electron microscopy (Miller et al., 1978) that bromobenzene induced a lesion which is confined morphologically to acinar zone 3 hepatocytes, it is conceivable that functional alterations might have occurred in acinar zone 1 and acinar zone 2 in spite of their morphological integrity. This possibility was tested by measuring gluconeogenesis in 
isolated hepatocytes and by determining the capacity for removal of ICG in perfused livers. Gluconeogenesis from lactate was determined in a sub-population of hepatocytes previously shown to represent wellpreserved cells probably originating from acinar zone 1 hepatocytes (Gumucio et al., 1978b; Wanson et al., 1975). As expected from functionally intact cells, the capacity for gluconeogenesis in this cell population was similar in controls and after bromobenzene. In addition, the reduction of the functional mass following bromobenzene administration as determined by the removal of ICG (Rikkers and Moody, 1974) was approximately $28 \%$, in agreement with a volume fraction of necrosis representing about $35 \%$ of the volume of the liver. Furthermore, the reduction in the capacity for bile salt removal was also about $30 \%$. Thus, both morphological and functional criteria suggested integrity of acinar zone 1 and zone 2 hepatocytes.

At $\left[{ }^{14} \mathrm{C}\right]$ taurocholate loads between 0.025 and $1.0 \mu \mathrm{mol} / \mathrm{kg}$, a range which encompassed physiological bile salt loads (Olivecrona and Sjovall, 1959; Okishio and Nair, 1966), a constant percentage representing 13-18\% of the injected dose appeared in the hepatic vein effluent after bromobenzene damage of the centrilobular area. This suggested that acinar zone 3 hepatocytes in the intact rat contributed to the removal of at least $13-18 \%$ of the injected dose of taurocholate; about $85 \%$ of the taurocholate load was therefore removed from sinusoidal blood before reaching the acinar zone 3 . Thus, a gradient of taurocholate concentrations developed between acinar zone 1 and acinar zone 3 hepatocytes, regardless of whether zone 1 and zone 2 hepatocytes removed a constant percentage of the injected dose. In contrast, at higher loads of $\left[{ }^{14} \mathrm{C}\right]$ taurocholate the percentage of the injected dose removed by livers of each group decreased progressively, suggesting that the uptake system was approaching saturation (Reichen and Paumgartner, 1975). Thus, it is likely that saturation of bile salt uptake occurs as a sequential phenomenon from acinar zone 1 to acinar zone 3 hepatocytes.

$\left[{ }^{14} \mathrm{C}\right]$ Taurocholate removal was also determined after the administration of carbon tetrachloride, another centrilobular cell toxicant (Oberling and Rouiller, 1967). The percentage of the injected dose of $\left[{ }^{14} \mathrm{C}\right]$ taurocholate removed after carbon terachloride was approximately $85 \%$, and thus was similar to that observed after bromobenzenc administration. The slight difference in the percentage of the injected dose removed by the two toxicants might be explained by the smaller volume fraction of necrosis induced by carbon tetrachloride.

As previously reported in experiments performed in rivo (Gumucio et al., 1978a), bile flow decreased by about $50 \%$ after acinar zone 3 damage by either bromobenzene or carbon tetrachloride. These findings support the proposal that centrilobular hepatocytes, although transporting only a small percentage of the acinar load of bile salts, do contribute to the genesis of canalicular bile flow.

\section{$\triangle$ CKNOWLEDGMENTS}

The authors wish to thank Mrs. Elizabeth Perry for editorial and secretarial help; the Pulmonary Function Laboratory, Department of Internal Medicine, University of Michigan for the use of their equipment, and Dr. Sidney J. Katz for the preparation of histological specimens. We also wish to thank Miss Francoise Magne and Miss Maryvonne Senac for their help in part of the experiments. This work was funded in part by Grant 2 ROI AM18409-04 from the National Institute of Health.

\section{REFERENCES}

Chalkley, H. W. (1944). Method for the quantitative morphologic analysis of tissues. $J$. Nat. Cancer Inst. 4, 47-53.

Cornell, R. O., and Filkins, J. P. (1974). Characterization of gluconeogenesis in enzymatically isolated parenchymal cells of rat liver. Proc. Soc. Exp. Biol. Med. 145, 203-209.

Goresky, C. A., Back, G. G., and NadeaU, B. E. (1973). On the uptake of materials by the intact liver. The transport and net removal of galactose. J. Clin. Invest. 52, 991-1009. 
Gumucio, J. J., Balabaud, C. P., Miller, D. L., DeMason, L. J., Appelman, H., Stoecker, T. J., aND FranzBLAU, D. R. (1978a). Bile secretion and liver cell heterogeneity in the rat. J. Lab. Clin. Med. 91, 350-362.

Gumucio, J. J., DeMason, L. J., Miller, D. L., Krezoski, S. O., AND Keener, N. (1978b). Induction of cytochrome $P-450$ in a selective subpopulation of hepatocytes. Amer. J. Physiol. 234, C102-109.

HaNKS, J. H.; AND Wallace, R. E. (1949). Relation of oxygen and temperature in the preservation of tissues by refrigeration. Proc. Soc. Exp. Biol. Med. 71, 196-201.

Heaton, K. W., (ed.) (1972.). Methodology. In Bile Salts in Health and Disease, pp. 42--51. Williams $\&$ Wilkins, Baltimore.

Lowry, H. O., Rosebrough, N. J., Farr, A. L., AND RANDALL, R. J. (1951). Protein measurement with the Folin phenol reagent. J. Biol. Chem. 193, 265-275.

Miller, D. L., Harasin, J. M., and Gumucio, J. J. (1978). Bromobenzene-induced zonal necrosis in the hepatic acinus. Exp. Mol. Pathol. 29, 358-370.

Oberling, C., And Rouiller, C. (1967). Les effets de l'intoxication aigue au tetrachlorure de carbone sur le foie de rat. Etude au microscope electronique. Ann. Anat, Pathol, 1, 401-427.

OKishio, T., AND NaIR, P. (1966). Studies on bile acids, Some observations on the intracellular localization of major bile acids in rat liver. Biochemistry 5, 3662-3666.
Olivecrona, T., and Sjovall, J. (1959). Bile salts in portal blood. Acta Physiol. Scand. 46, 284-290.

Paumgartner, G., Probst, R., Kraines, R., and LEEVY, C. M. (1970). Kinetics of indocyanine green removal from the blood. Ann. N.Y. Acad. Sci. 170, 134-147

RAPPAPORT, A. M. (1975). Anatomic considerations. In Disease of the Liver (L. Schiff, ed.), Vol. 1, pp. 1-50. Lippincott, Philadelphia.

Reichen, J., And Paumgartner, G. (1975). Kinetics of taurocholate uptake by the perfused rat liver. Gastroenterology 68, 132-136.

REID, W. D., AND KRISHNA, G. (1973). Centrilobular hepatic necrosis related to covalent binding of halogenated aromatic hydrocarbons. Exp. Mol. Pathol. 18, 80-99.

RiKkeRs, L. F., AND MOODY, F. G. (1974). Estimation of functional hepatic mass in resected and regenerating rat liver. Gastroenterology 67, 691-701.

SCHOLz, R. (1968). Untersuchungen zur Redorkompartmentierung bei der Hamoglobinfrei Perfundierten Rattenleber. In Stoffwechsel der Isoliert Perfundierten Leber (R. Scholz and W. Slaib, eds.), pp. 25-53. Springer-Verlag, Berlin/Heidelberg/ New York.

Tavoloni, J., Reed, J. S., AND Boyer, J. D. (1978). Hemodynamic effect on determinants of bile secretion in isolated rat liver. Amer. J. Physiol. 234, E584.

Wanson, J. C., Drochmans, P., May, C., Penasse, W., AND Popowsky, A. (1975). Isolation of centrilobular and perilobular hepatocytes after phenobarbital treatment. J. Cell. Biol. 66, 23-41. 